\title{
Development of a questionnaire survey to evaluate lower limb function of patients with knee osteoarthritis
}

\author{
Yusuke Suzuki $^{1} \cdot$ Hirotaka lijima ${ }^{1,2} \cdot$ Yuto Tashiro $^{1} \cdot$ Yuu Kajiwara $^{1} \cdot$ Hala Zeidan $^{1} \cdot$ Kanako Shimoura $^{1}$. \\ Yuichi Nishida $^{1} \cdot$ Tsubasa Bito $^{1} \cdot$ Kengo Nakai $^{1}$ • Masataka Tatsumi ${ }^{1}$ - Soyoka Yoshimi ${ }^{1} \cdot$ Tadao Tsuboyama $^{1}$. \\ Tomoki Aoyama ${ }^{1}$
}

Received: 15 June 2018 / Revised: 12 July 2018 / Accepted: 20 July 2018 / Published online: 8 August 2018

(C) The Author(s) 2018

\begin{abstract}
This study aimed to develop a self-questionnaire index relevant to lower limb functional assessment reflecting clinical symptoms and activity restrictions associated with activities of daily living (ADL) for patients with knee osteoarthritis. This cross-sectional study enrolled patients with knee osteoarthritis (Kellgren/Lawrence grade $\geq 1$ ). Participants evaluated clinical symptoms and activity restrictions using self-reported questionnaires. Radiographic evaluation, knee joint range of motion (ROM), and lower limb muscle strength were assessed. Associations between clinical symptoms, activity restrictions, and knee and hip joint function were evaluated using multiple and logistic regression analysis. Overall, 142 participants were included in the final analysis. Patients with knee pain while rising from a chair had lower knee and hip extension strength (knee extension $\beta=-0.28$; $95 \%$ confidence interval (CI), -0.41 to $-0.14 ; P<0.0001$; hip extension $\beta=-0.26 ; 95 \% \mathrm{CI},-0.42$ to $-0.08 ; P=0.0034$ ), and restricted knee extension ROM (odds ratio $[\mathrm{OR}]=2.17 ; 95 \% \mathrm{CI}, 1.02-4.63 ; P=0.041$ ). Patients with knee pain during stair climbing, turning or who were unable to stand on one leg without external support had reduced hip abduction muscle strength ( $\beta=-0.17 ; 95 \% \mathrm{CI},-0.27$ to $-0.07 ; P=0.0008$ ). Patients with knee pain while rising from a chair or stepping showed more severe knee joint degeneration on radiographic evaluation ( $\mathrm{OR}=3.26 ; 95 \% \mathrm{CI}, 1.11-10.91 ; P=0.03)$. The self-questionnaire index reflected clinical symptoms and activity restrictions associated with ADL and was significantly associated with lower limb function in individuals with knee osteoarthritis.
\end{abstract}

Keywords Activities of daily living $\cdot$ Knee osteoarthritis $\cdot$ Muscle $\cdot$ Pain $\cdot$ Questionnaire $\cdot$ Range of motion

\section{Introduction}

Knee osteoarthritis is a painful disease mainly caused by the degeneration of articular cartilage. The prevalence in Japanese individuals over 60 years old is $47.0 \%$ in males and $70.2 \%$ in females, indicating it is a common disease [1]. Worsening of

Electronic supplementary material The online version of this article (https://doi.org/10.1007/s10067-018-4229-5) contains supplementary material, which is available to authorized users.

Tomoki Aoyama

blue@hs.med.kyoto-u.ac.jp

1 Department of Physical Therapy, Human Health Sciences, Graduate School of Medicine, Kyoto University, 53 Kawahara-cho, Shogoin, Sakyo-ku, Kyoto 606-8507, Japan

2 Department of System Design Engineering, Keio University, Yokohama, Japan the severity of knee osteoarthritis leads to decreased activity and becomes a major factor in increasing care risks suggesting there is a need for prevention of onset or progression [2]. However, effective treatment and preventive methods have not been established, and symptomatic treatment remains the main approach.

The cause of knee osteoarthritic pain has yet to be determined. Categorization of causes based on past reports divides etiology into organic factors such as cartilage degeneration and osteophytes [3] and factors involving surrounding tissues. Indeed, patients with knee osteoarthritis experience muscle weakness of the quadriceps [4] and hip joint muscles [5], as well as range of motion (ROM) limitation of the knee joint [6], which leads to knee pain and dysfunction.

In clinical practice, not only medical history and radiographic evaluation [7] but also functional evaluation of muscle strength [8], tenderness [9], and balancing ability [10] are part of the clinical evaluation of patients with knee osteoarthritis. 
Furthermore, non-drug therapies, including patient education, weight loss, and exercise are recommended. Thus, treatment for osteoarthritis is broadly classified into drug therapy and non-drug therapy [11]. Among non-drug therapies, exercise has been reported to be effective $[12,13]$. In particular, muscular strength training of the knee and hip joint muscles significantly reduced knee osteoarthritis pain [14] and acute hamstring stretch improved knee extension range, peak torque, and stiffness in the final $10 \%$ of knee extension ROM [15]. However, patients with severe knee joint damage did not benefit from exercise therapy [16]. Thus, functional evaluation of lower limb muscle strength, joint ROM, and assessment of the severity of knee joint degeneration is important in exercise therapy for osteoarthritis, although it is conceivable that the time and expensive diagnostic systems necessary for comprehensive assessment and non-standardization of treatment may ultimately lead to a subjective evaluation by the clinician. Therefore, predicting lower limb function in patients with osteoarthritis using a simple questionnaire can possibly assist functional evaluation in the clinical setting.

The evaluation indices for pain and dysfunction in knee osteoarthritis include the Western Ontario and McMaster Universities Arthritis Index (WOMAC) [17], the Medical Outcomes Study 36-item Short Form Health survey (SF-36) [18], and the Japanese knee osteoarthritis measure (JKOM) in Japan [19]. The WOMAC and JKOM are indexes for evaluating pain, stiffness, and functional impairment caused by osteoarthritis of the knee. The SF-36 is an index used to evaluate comprehensive health including knee osteoarthritis. In contrast, there are no evaluation indices currently available focusing on functional evaluation, in particular with respect to the condition of the knee and the hip joint muscles in patients with knee osteoarthritis. Thus, an index capable of evaluating lower limb function, in particular the strength of knee and hip joint muscles, knee joint ROM, and the severity of knee joint degeneration in patients with knee osteoarthritis, with generalizable contents would be useful for functional evaluation in the clinical setting.

Physical function is significantly associated with low levels of physical activity in patients with knee osteoarthritis [20]. Moreover, the degree of knee pain differs depending on the type of physical activity in patients with knee osteoarthritis [21]. Therefore, clinical symptoms such as knee pain, physical functions such as lower limb function, and physical activity, including ADL, are expected to be closely associated. Then, once potential questions assessing clinical symptoms and activity restrictions associated with ADL are developed, it is hypothesized that lower limb functions such as strength of knees and hip muscles, knee joint ROM, and severity of knee joint may be reflected in the responses of specific questions.

Thus, the purpose of this study was to develop a selfquestionnaire index with generalizable contents reflecting clinical symptoms and activity restrictions associated with
ADL for patients with knee osteoarthritis. Moreover, we also aimed to confirm the relevance of the survey in assessing lower limb function including strength of knee and hip muscles, knee joint ROM, and severity.

\section{Methods}

\section{Study design}

This was a cross-sectional study involving subjects with knee osteoarthritis.

\section{Participants}

Elderly participants reporting current knee pain were identified by a survey via mails and were invited to attend a research site at Kyoto University in September and October 2017. The ethics committee of Kyoto University approved the study (No. C1297), and written informed consent was obtained from all participants before enrollment. All recruited participants had a history of pain in one or both knees. The eligibility criteria included (1) age $\geq 45$ years; (2) knees with radiographic osteoarthritis (i.e., Kellgren/Lawrence $[\mathrm{K} / \mathrm{L}]$ grade $\geq 1$ according to the original version [22]) in one or both knees in the medial tibiofemoral compartment, evaluated using weight-bearing anteroposterior radiographs; and (3) an ability to walk independently on a flat surface without any ambulatory assistive device. Participants with bilateral knee osteoarthritis were not differentiated from the unilateral cases. The exclusion criteria included (1) history of knee surgery, (2) rheumatoid arthritis, (3) periarticular fracture, (4) presence of neurological problems, or (5) knee with pre-radiographic osteoarthritis (i.e., K/ $\mathrm{L}$ grade 0 ).

\section{Outcome measurements}

The following outcome measurements were evaluated: (1) demographic data, (2) radiographic evaluation, (3) knee joint ROM, (4) measurement of lower limb muscle strength, (5) results of self-reported questionnaires to investigate clinical symptoms and activity restrictions associated with ADL.

\section{Demographic data}

Data on age, sex, and height were self-reported by patients. Weight was measured on a scale with participants wearing their clothes, but without shoes. The body mass index (BMI) was calculated by dividing the weight by the square of the height. Severity of knee pain and self-reported physical function were evaluated using the JKOM. The JKOM is a patientbased, self-answered evaluation scoring system that assesses "pain and stiffness" (8 questions, 0-32 points), "activities of 
daily living" (10 questions, 0-40 points), "participation in social activities" (5 questions, 0-20 points), and "general health conditions" ( 2 questions, $0-8$ points), with a maximum score of 100 points in a person-specific assessment [19]. The concurrent and construct validities of the JKOM were established by comparing the WOMAC and the SF-36 surveys [19].

\section{Radiographic evaluation}

Anteroposterior radiographs of both knees in the fully extended weight-bearing and foot map positions were obtained after enrollment. The radiographic severity of the medial compartment in the tibiofemoral joint was assessed by a trained examiner. The $\mathrm{K} / \mathrm{L}$ grade was scored as follows: 0 = normal; 1 = doubtful joint space narrowing (JSN) and possible osteophyte; $2=$ definite osteophyte and possible JSN; $3=$ multiple osteophytes, definite JSN, some sclerosis, and possible deformity of bone ends; and $4=$ large osteophyte, marked JSN, severe sclerosis, and definite deformity of bone ends. The intrarater and interrater agreements for the $\mathrm{K} / \mathrm{L}$ grade determination were excellent (intrarater, $\mathrm{k}: 0.90$ ) [23].

\section{Knee joint range of motion}

The flexion and extension ROM of both knee joints were measured passively in the supine position using standard goniometric procedures, following previously validated methods [24]. The goniometer axis was placed in line with the center of the knee, the fixed arm aligned with the greater trochanter and lateral femoral condyle, and the mobile arm aligned with the head of the fibula and lateral malleolus. Negative values of knee extension ROM indicated a lack of full extension of the knee joint. Excellent intraclass correlation coefficients for flexion (0.99) and extension (0.98) have been reported for goniometric measurements of passive ROM [24].

\section{Muscle strength}

Maximum isometric knee extensor strengths in both legs were measured using hand-held dynamometry (HHD) in accordance with a previously validated method for communitydwelling elderly fallers [25]. HHD is a simple tool for objectively quantifying muscle strength and is widely used in clinical practice. Maximum force was recorded in Newton meters (Nm) and two repetitions were performed for each test. Participants were instructed to remain seated in an upright position.

To measure maximum isometric knee extensor strength, the knee was placed at $90^{\circ}$ flexion, with the HHD attached $10-\mathrm{cm}$ proximal to the lateral malleolus and held in place with an inelastic strap that was looped around the therapy bed and fastened. The length of the straps allowed for an isometric contraction to be performed with the knee at $90^{\circ}$ of flexion during testing. Participants were instructed to extend their leg for $5 \mathrm{~s}$. Strong verbal encouragement was provided to ensure maximum effort.

To measure the maximum isometric hip extensor strength, the patient was instructed to lie supine on the therapy bed. The hip was placed in slight flexion with the knee straight in the neutral position of external-internal rotation, with the HHD device attached just superior to the lateral epicondyle of the posterior femur of the lower leg and held inwards. The patient was instructed to extend his/her leg for $5 \mathrm{~s}$. Strong verbal encouragement was provided to ensure maximum effort. The other examiner supported the patient on the contralateral limb.

To measure the maximum isometric hip abduction strength, the patient was instructed to lie supine on the therapy bed. The hip was placed in the neutral position of flexion-extension and external-internal rotation with the knee straight, and with the HHD device attached just superior to the lateral epicondyle of the femur of the upper leg and held inwards. The hip and knee of the lower leg were slightly flexed. The patient was instructed to abduct the leg for $5 \mathrm{~s}$. Strong verbal encouragement was provided to ensure maximum effort.

To provide the value of the moment of force $(\mathrm{Nm})$, the lever arm (length of the femur or tibia) between the knee joint and the HHD device was manually measured, and subsequently normalized to the body mass $(\mathrm{Nm} / \mathrm{kg})$. The average of two repetitions was used for statistical analysis. Strong verbal encouragement was provided to ensure maximum effort.

\section{Self-reported questionnaires to investigate clinical symptoms and activity restrictions associated with activities of daily living}

To investigate the relationship between clinical symptoms and activity restrictions associated with ADL, and knee and hip muscle function in individuals with knee osteoarthritis, physicians and physiotherapists extracted some of the survey responses and associated these with physical functions. Based on this content, a self-reported questionnaire was designed to investigate the following clinical symptoms and activity restrictions associated with ADL: (1) presence or absence of knee pain while rising from a chair; (2) presence or absence of knee pain while stair climbing or turning, or whether standing on one leg was possible for $\geq 60 \mathrm{~s}$ by touching an external support; (3) presence or absence of knee pain while rising from a chair or stepping. We investigated whether all the subjects responded (Yes/No) to the above questions, and the responses were used for statistical analysis.

\section{Sample size}

The sample size calculation for multiple linear regression analysis was determined using the $G^{*}$ Power 3 
program (Heinrich-Heine-Universität Düsseldorf, Düsseldorf, Germany) [26] to yield a power of $80 \%$, significance level of 0.05 , and moderate effect size $(f=0.15)$ [27]. Moreover, the sample size calculation of logistic regression analysis was determined based on four independent variables [28].

We defined a theoretical sample size of 85 participants. To allow for a potential data loss of $20 \%$, the required sample size was 102 participants.

\section{Statistical analysis}

To minimize any bias produced by similarities between the right and left knees of the same patient, only one knee per patient (index knee) was analyzed. The index knee was defined as the more painful knee in either the past or present history. If patients felt that their knees were equally painful, the index knee was selected randomly using a computer-generated permuted block randomization scheme [29].

The characteristics of subjects included in the study are described as the mean \pm standard deviation (SD) for continuous variables, and as number and percentage for nominal variables and ordinal variables.

The analysis of the relationship between clinical symptoms and activity restrictions associated with ADL, and the knee and hip muscle function is shown in Supplementary Table 1.

1. The association between knee pain while rising from a chair and strength of knee and hip extension. Multiple regression analysis was performed with the strength of knee extension and hip extension as dependent variables and binary variabilization of the presence or absence of knee pain while rising from a chair as the independent variable.

2. The association between knee pain while stair climbing or turning or with an inability to stand on one leg and the strength of hip abduction. Multiple regression analysis was performed with the strength of hip abduction as a dependent variable and binary variabilization of the presence or absence of knee pain while stair climbing or turning or the result of the ability or inability to stand on one leg longer than $60 \mathrm{~s}$ with external support as the independent variable.

3. The association between knee pain while rising from a chair and the range of motion of knee extension. Logistic regression analysis was performed with binary variabilization of knee extension ROM (not less than the normal range $\left[\geq 0^{\circ}\right.$ or more] or less than the normal range $\left[<0^{\circ}\right]$ ) as the dependent variable and binary variabilization of the presence or
Table 1 Characteristics of subjects ${ }^{\mathrm{a}}$

\begin{tabular}{ll}
\hline Variables & $\begin{array}{l}\text { Subjects } \\
(n=142)\end{array}$ \\
\hline Age (years) & $65.75 \pm 9.02$ \\
Women (\%) & $110(77.4)$ \\
Height $(\mathrm{cm})$ & $158.25 \pm 7.49$ \\
Weight $(\mathrm{kg})$ & $58.71 \pm 11.69$ \\
BMI $\left(\mathrm{kg} / \mathrm{cm}^{2}\right)$ & $23.36 \pm 3.83$ \\
VAS of knee pain $(\mathrm{mm})$ & $34.58 \pm 22.8$ \\
Duration of knee pain $(\mathrm{months})$ & $42.62 \pm 60.33$ \\
K/L grade & \\
Grade 1 (\%) & $66(46.5)$ \\
Grade 2 (\%) & $50(35.2)$ \\
Grade $3(\%)$ & $21(14.8)$ \\
Grade $4(\%)$ & $5(3.5)$ \\
ROM of knee extension $\left({ }^{\circ}\right)^{\mathrm{b}}$ & $-2.48 \pm 5.57$ \\
ROM of knee flexion $\left(^{\circ}\right)$ & $143.45 \pm 10.08$ \\
Strength of knee extension $(\mathrm{Nm} / \mathrm{kg})$ & $1.15 \pm 0.44$ \\
Strength of hip extension $(\mathrm{Nm} / \mathrm{kg})$ & $1.34 \pm 0.53$ \\
Strength of hip abduction $(\mathrm{Nm} / \mathrm{kg})$ & $0.72 \pm 0.26$ \\
JKOM (point) & $16.97 \pm 9.41$ \\
\hline
\end{tabular}

$V A S$ visual analogue scale, $R O M$ range of motion, JKOM Japanese knee osteoarthritis measure, $B M I$ body mass index

${ }^{\mathrm{a}}$ Values are mean $\pm \mathrm{SD}$ or the number (percentage)

${ }^{\mathrm{b}}$ A negative value for ROM of knee extension indicates no extension of the knee

absence of knee pain while rising from a chair as the independent variable.

4. The association between knee pain while rising from a chair or stepping and K/L grade. Logistic regression analysis was performed with binary variabilization of the result of radiographic evaluation assessed by the $\mathrm{K} / \mathrm{L}$ grade (early [grade $1-2$ ] or severe [grade $3-4$ ]) as dependent variables and binary variabilization of the presence or absence of knee pain while rising from a chair or while stepping as independent variables.

For the analyses of 1 and 2 above, multivariate analysis was carried out using age- and sex-adjusted variables, and for the analyses of 3 and 4, multivariate analysis was performed using age-, sex-, and BMI-adjusted variables, respectively.

Moreover, the relationships between each outcome and the JKOM sub-scale (pain and stiffness) were confirmed by multiple regression analysis.

Data analyses were performed using JMP Pro version 12.2 (SAS Institute, Cary, NC, USA). A $P$ value $<0.05$ was considered statistically significant. 
Table 2 The association between knee pain while rising from a chair and strength of knee extension

\begin{tabular}{lllll}
\hline Variables & $\begin{array}{l}\text { Without knee pain }{ }^{\mathrm{a}} \\
(n=69)\end{array}$ & $\begin{array}{l}\text { With knee pain } \\
(n=73)\end{array}$ & $\begin{array}{l}\text { Unadjusted } \beta \\
(95 \% \mathrm{CI})\end{array}$ & $\begin{array}{l}\text { Adjusted } \beta \\
(95 \% \mathrm{CI})\end{array}$ \\
\hline Knee pain while rising from a chair & $1.30 \pm 0.40$ & $1.01 \pm 0.43$ & $-0.28(-0.42$ to -0.14$)$ & $-0.28(-0.41$ to -0.14$)$ \\
\hline
\end{tabular}

${ }^{\text {a }}$ Values are mean $\pm \mathrm{SD}$

${ }^{\mathrm{b}}$ Adjusted for age (years) and sex

\section{Results}

Overall, 296 participants were recruited, of which 107 (36.1\%) were excluded because of the absence of knee pain, $3(1.0 \%)$ were excluded due to a history of knee surgery, $11(4.0 \%)$ were excluded because of preradiographic osteoarthritis $(\mathrm{K} / \mathrm{L}$ grade $=0)$, and 33 $(11.1 \%)$ were excluded because of missing data. Thus, a total of 142 participants were included in the final analysis. Baseline demographic and clinical characteristics for the 142 participants are shown in Table 1.

There was no significant relationship between any outcome and the JKOM sub-scale (pain and stiffness) (data not shown).

\section{The association between knee pain while rising from a chair and strength of knee and hip extension}

When adjusted by age and sex, patients with knee pain while rising from a chair had significantly decreased strength of knee extension and hip extension (strength of knee extension $\beta=-0.28 ; 95 \%$ [confidence interval] CI, -0.41 to $-0.14 ; P$ $<0.0001$; strength of hip extension $\beta=-0.26$; $95 \% \mathrm{CI}-0.42$ to $-0.08 ; P=0.0034)$ (Tables 2 and 3 ).

\section{The association between knee pain while stair climbing or turning or with the inability to stand on one leg, and strength of hip abduction}

When adjusted by age and sex, patients with knee pain while stair climbing or turning or with the inability to stand on one leg for $>60 \mathrm{~s}$ with external support had significantly decreased hip abduction strength $(\beta=-0.17 ; 95 \% \mathrm{CI},-$ 0.27 to $-0.07 ; P=0.0008$ ) (Table 4 ).

\section{The association between knee pain while rising from a chair and range of motion of knee extension}

When adjusted by age, sex, and BMI, patients with knee pain while rising from a chair had a significantly decreased ROM of the knee extension (odds ratio $[\mathrm{OR}]=2.17 ; 95 \% \mathrm{CI}, 1.02$ 4.63; $P=0.041$ ) (Table 5).

\section{The association between knee pain while rising from a chair or stepping, and K/L grade}

When adjusted by age, sex, and BMI, patients with knee pain while rising from a chair or stepping had a significantly worse $\mathrm{K} / \mathrm{L}$ grade $(\mathrm{OR}=3.26 ; 95 \% \mathrm{CI}, 1.11-10.91 ; P=0.03)$ (Table 6).

\section{Discussion}

Our study showed that there was a significant relationship between self-reported questionnaires investigating clinical symptoms and activity restrictions associated with ADL and lower limb function such as the knee and hip muscle strength, knee joint ROM, and the severity of degeneration of the knee joint.

The association between knee pain while rising from a chair and knee and hip extension strength was evaluated. Activities of knee and hip extension muscles were observed in the standing position or when rising from a chair. Previous studies have shown that declining knee extension strength is a

Table 3 The association between knee pain while rising from a chair and strength of hip extension

\begin{tabular}{lllll}
\hline Variables & $\begin{array}{l}\text { Without knee pain } \\
(n=69)\end{array}$ & $\begin{array}{l}\text { With knee pain }^{\mathrm{a}} \\
(n=73)\end{array}$ & $\begin{array}{l}\text { Unadjusted } \beta \\
(95 \% \mathrm{CI})\end{array}$ & $\begin{array}{l}\text { Adjusted } \beta \\
(95 \% \mathrm{CI})\end{array}$ \\
\hline Knee pain while rising from a chair & $1.48 \pm 0.54$ & $1.21 \pm 0.50$ & $-0.27(-0.44$ to -0.09$)$ & $-0.26(-0.42$ to -0.08$)$ \\
\hline
\end{tabular}

${ }^{\text {a }}$ Values are mean $\pm \mathrm{SD}$

${ }^{\mathrm{b}}$ Adjusted for age (years) and sex 
Table 4 The association between knee pain while stair climbing or turning or inability to stand on one leg and strength of hip abduction

\begin{tabular}{lllll}
\hline Variables & $\begin{array}{l}\text { Not applicable } \\
(n=33)\end{array}$ & $\begin{array}{l}\text { Applicable } \\
(n=109)\end{array}$ & $\begin{array}{l}\text { Unadjusted } \beta \\
(95 \% \mathrm{CI})\end{array}$ & $\begin{array}{l}\text { Adjusted } \beta \\
(95 \% \mathrm{CI})^{\mathrm{b}}\end{array}$ \\
\hline $\begin{array}{l}\text { Knee pain while stair climbing or turning } \\
\text { or inability to stand on one leg }\end{array}$ & $0.86 \pm 0.26$ & $0.68 \pm 0.25$ & $-0.18(-0.28$ to -0.08$)$ & $-0.17(-0.27$ to -0.07$)$ \\
\hline $\begin{array}{l}\text { a Values are mean } \pm \mathrm{SD} \\
\mathrm{b} \text { Adjusted for age (years) and sex }\end{array}$ & & & \\
\end{tabular}

commonly observed phenomenon in patients with knee osteoarthritis and have reported that declining knee extension strength also affects the motion of rising from a chair [30]. In patients with knee osteoarthritis, a significant increase in pain and a decrease in quadriceps muscle strength were observed during a 1-year follow-up [31]. A previous report indicated that the value of the quadriceps muscle strength was related to the progress of knee osteoarthritis and instability of the knee joint [32]. These reports suggest that there is a significant relationship between knee osteoarthritic pain and quadriceps muscle strength. Therefore, patients with knee pain while rising from a chair had decreased knee extension strength (quadriceps muscle).

Previous studies have shown that patients with knee osteoarthritis have higher hip extension torque compared to the control group on standing from a chair movement [33]. This report suggests that patients with knee osteoarthritis compensate muscle weakness of knee extension strength with hip extension strength while rising from a chair. Therefore, when the strength of hip extension decreases, the burden on the already weakened knee extension muscles increases, which causes knee pain during standing motion from the chair.

For these reasons, patients with knee pain while rising from a chair had a decrease in the strength of knee and hip extension muscles.

The association between knee pain while stair climbing or turning or the inability to stand on one leg and strength of hip abduction was also evaluated. The hip abductor muscle is a connecting muscle between the pelvis and the lower limbs and is the muscle that contributes to the stability of the pelvis on the frontal plane [34]. According to previous studies, the hip joint angle at which the torque of the hip abductor muscle becomes the maximum is a $10^{\circ}$ adduction [35]. This report suggests that the torque of the hip abductor muscle is maximally required at the time of single leg standing. Therefore, subjects who were unable to stand on one leg by touching an external support had decreased strength of hip abduction muscles.

The hip abductor muscle functions to support weight through the pelvis [34]. Moreover, it has been reported that the load applied to the hip abductor muscle at the time of ascending and descending stairs is 5 to 6 times larger than that of usual activities [36]. Furthermore, previous studies have reported that subjects with knee osteoarthritis who had poor results on the "get-up-and-go" (GUG) test with direction change had significantly decreased strength of the hip abductor muscle [37]. Therefore, hip abductor muscular strength is considered important for stair climbing or turning.

The association between knee pain while rising from a chair and ROM of knee extension was considered. Previous studies have reported that patients with knee osteoarthritis have significant contraction of the hamstrings on cocontraction of the quadriceps and hamstrings [38]. Patients with knee osteoarthritis develop excessive co-contractions of knee joint muscles when rising from a chair; in particular, excessive hamstring activity occurs. This excessive activity of the hamstrings while rising from a chair is a pain escape reaction by restricting the knee joint ROM [39]. The hamstring is an agonist of knee flexion. Excessive activity and tension of hamstrings may cause shortening of hamstrings and restriction of knee extension ROM. For these reasons, patients with knee pain while rising from a chair seemed to have found a restriction of knee extension ROM.

The association between knee pain while rising from a chair or while stepping and $\mathrm{K} / \mathrm{L}$ grade was considered.

Table 5 The association between knee pain while rising from a chair and range of motion of knee extension

\begin{tabular}{|c|c|c|c|c|}
\hline Variables & Without knee pain ${ }^{\mathrm{a}}$ & With knee pain ${ }^{\mathrm{a}}$ & $\begin{array}{l}\text { Unadjusted odds } \\
(95 \% \mathrm{CI})\end{array}$ & $\begin{array}{l}\text { Adjusted odds } \\
(95 \% \text { CI })^{\mathrm{b}}\end{array}$ \\
\hline Knee pain while rising from a chair & $69(48.6)$ & $73(51.4)$ & $2.7(1.35-5.52)$ & $2.17(1.02-4.63)$ \\
\hline
\end{tabular}


Table 6 The association between knee pain while rising from a chair or stepping and $\mathrm{K} / \mathrm{L}$ grade

\begin{tabular}{|c|c|c|c|c|}
\hline Variables & Without knee pain ${ }^{\mathrm{a}}$ & With knee pain ${ }^{a}$ & $\begin{array}{l}\text { Unadjusted odds } \\
(95 \% \mathrm{CI})\end{array}$ & $\begin{array}{l}\text { Adjusted odds } \\
(95 \% \text { CI })^{\mathrm{b}}\end{array}$ \\
\hline Knee pain while rising from a chair or stepping & $57(40.1)$ & $85(59.9)$ & $2.61(1.02-7.58)$ & $3.26(1.11-10.91)$ \\
\hline
\end{tabular}

${ }^{\text {a }}$ Values are the number (percentage)

${ }^{\mathrm{b}}$ Adjusted for age (years), sex, and body mass index

Previous studies have reported that the thickness of the femoral articular cartilage correlates with the strength of the quadriceps [40]. Moreover, according to previous studies, in patients with osteoarthritis of the knee, the lower the muscle strength of the quadriceps muscle, the worse the condition of the knee joint on radiographic evaluation [41]. There is a close relationship between the quadriceps, which is the knee extension muscle and the severity of the knee joint in radiographic evaluation. As there is a significant relationship between knee pain while rising from a chair and muscle weakness of the quadriceps muscle, those with knee pain while rising from a chair showed a greater severity of the knee joint damage on radiographic evaluation.

Furthermore, a previous study showed that higher peak and impulse of knee adduction moment (KAM) were each associated with worsening of medial bone marrow lesions [42]. Moreover, subjects with higher peak and impulse of KAM also reported increased knee pain [43, 44]. For this reason, since the KAM increases when standing on one leg, stepping, and walking, knee pain while stepping in these patients was associated with the severity of the knee joint damage on radiographic evaluation.

A significant relationship was found between the selfquestionnaire index developed in this study and lower limb function such as strength of knee and hip muscles, knee joint ROM, and severity of the knee joint damage, indicating that a difference in lower limb function could be reflected by specific survey question items. Therefore, by combining these question items, it may be possible to evaluate lower limb function for each subject and the self-questionnaire index may be a useful and a time-saving tool for functional evaluation, bypassing the requirement of an expensive diagnostic system and standardization of treatment in the clinical setting. By applying the function evaluation of this questionnaire, it would be possible to provide a home-exercise program, such as knee and hip muscular strength training and hamstring stretching, based on the severity of the knee joint, which is personalized for each individual.

There are several limitations to this study. First, participants in this study were motivated individuals, because they actively enrolled for the study by responding to e-mails and were recruited via public relation magazines; thus, there may have been a selection bias. Second, self-reported questionnaires may not always provide precise data due to recall bias. Third, this study was cross-sectional; therefore, any cause-effect relationship between knee pain accompanying daily activities and function of knee and hip muscles in individuals with knee osteoarthritis remains unknown. Further investigations, including prospective studies, are required to confirm our results.

\section{Conclusions}

In this study, a self-questionnaire index was developed to reflect the clinical symptoms and activity restrictions associated with ADL for patients with knee osteoarthritis with generalizable contents. The study also investigated the relevance of the index with regard to lower limb function such as strength of knee and hip muscles, knee joint ROM, and the severity of knee joint degeneration.

The self-questionnaire index was found to be significantly related to lower limb function in individuals with knee osteoarthritis. Moreover, as hypothesized in this study, the lower limb function such as strength of knee and hip muscles, knee joint ROM, and the severity of knee joint degeneration could be successfully assessed by specific target questions.

Combining these question items, it was possible to evaluate the lower limb function for each subject and to provide an individualized exercise program for each patient.

Acknowledgments The authors thank the students of Human Health Sciences at Kyoto University for their help with the data collection. We would like to thank Editage (www.editage.jp) for the English language editing.

Funding Funding was provided by Omron Healthcare Co., Ltd.

\section{Compliance with ethical standards}

The ethics committee of Kyoto University approved the study (No. C1297), and written informed consent was obtained from all participants before enrollment.

Disclosures None.

Open Access This article is distributed under the terms of the Creative Commons Attribution 4.0 International License (http:// creativecommons.org/licenses/by/4.0/), which permits unrestricted use, distribution, and reproduction in any medium, provided you give appropriate credit to the original author(s) and the source, provide a link to the Creative Commons license, and indicate if changes were made. 


\section{References}

1. Muraki S, Oka H, Akune T, Mabuchi A, En-yo Y, Yoshida M, Saika A, Suzuki T, Yoshida H, Ishibashi H, Yamamoto S, Nakamura K, Kawaguchi H, Yoshimura N (2009) Prevalence of radiographic knee osteoarthritis and its association with knee pain in the elderly of Japanese population-based cohorts: the ROAD study. Osteoarthr Cartil 17:1137-1143

2. Kauppila AM, Kyllonen E et al (2009) Disability in end-stage knee osteoarthritis. Disabil Rehabil 31:370-380

3. Felson DT, Lawrence RC, Dieppe PA et al (2000) Osteoarthritis: new insights. Part 1: the disease and its risk factors. Ann Intern Med 133:635-646

4. Baker KR, Xu L, Zhang Y, Nevitt M, Niu J, Aliabadi P, Yu W, Felson D (2004) Quadriceps weakness and its relationship to tibiofemoral and patellofemoral knee osteoarthritis in Chinese: the Beijing osteoarthritis study. Arthritis Rheum 50:1815-1821

5. Hinman RS, Hunt MA, Creaby MW, Wrigley TV, McManus FJ, Bennell KL (2010) Hip muscle weakness in individuals with medial knee osteoarthritis. Arthritis Care Res (Hoboken) 62:1190-1193

6. Dekker J, van Dijk GM, Veenhof C (2009) Risk factors for functional decline in osteoarthritis of the hip or knee. Curr Opin Rheumatol 21:520-524

7. Kessler S, Guenther KP, Puhl W (1998) Scoring prevalence and severity in gonarthritis: the suitability of the Kellgren \& Lawrence scale. Clin Rheumatol 17:205-209

8. Palmieri-Smith RM, Thomas AC, Karvonen-Gutierrez C, Sowers MF (2010) Isometric quadriceps strength in women with mild, moderate, and severe knee osteoarthritis. Am J Phys Med Rehabil 89:541-548

9. van Dijk GM, Veenhof C, Spreeuwenberg P, CARPA Study Group et al (2010a) Prognosis of limitations in activities in osteoarthritis of the hip or knee: a 3-year cohort study. Arch Phys Med Rehabil 91: 58-66

10. Hsieh RL, Lee WC, Lo MT, Liao WC (2013) Postural stability in patients with knee osteoarthritis: comparison with controls and evaluation of relationships between postural stability scores and international classification of functioning, disability and health components. Arch Phys Med Rehabil 94:340-346

11. Zhang W, Moskowitz RW, Nuki G, Abramson S, Altman RD, Arden N, Bierma-Zeinstra S, Brandt KD, Croft P, Doherty M, Dougados M, Hochberg M, Hunter DJ, Kwoh K, Lohmander LS, Tugwell P (2008) OARSI recommendations for the management of hip and knee osteoarthritis, PartII: OARSI evidence-based, expert consensus guidelines. Osteoarthr Cartil 16:137-162

12. Juhl C, Christensen R, Roos EM, Zhang W, Lund H (2014) Impact of exercise type and dose on pain and disability in knee osteoarthritis: a systematic review and meta-regression analysis of randomized controlled trials. Arthritis Rheumatol 66:622-636

13. Fransen M, McConnell S, Harmer AR, Van der Esch M, Simic M, Bennell KL (2015) Exercise for osteoarthritis of the knee. Cochrane Database Syst Rev 9(1):CD004376

14. Sled EA, Khoja L, Deluzio KJ, Olney SJ, Culham EG (2010) Effect of a home program of hip abductor exercises on knee joint loading, strength, function, and pain in people with knee osteoarthritis: a clinical trial. Phys Ther 90:895-904

15. Reid DA, PJ MN (2010) Effects of an acute hamstring stretch in people with and without osteoarthritis of the knee. Physiotherapy 96:14-21

16. Knoop J, Dekker J, van der Leeden M, van der Esch M, Klein JP, Hunter DJ, Roorda LD, Steultjens MPM, Lems WF (2014) Is the severity of knee osteoarthritis on magnetic resonance imaging associated with outcome of exercise therapy? Arthritis Care Res (Hoboken) 66:63-68
17. Bellamy N, Buchanan WW, Goldsmith CH, Campbell J, Stitt LW (1988) Validation study of WOMAC: a health status instrument for measuring clinically important patient relevant outcomes to antirheumatic drug therapy in patients with osteoarthritis of the hip or knee. J Rheumatol 15:1833-1840

18. Ware JE Jr, Sherbourne CD (1992) The MOS 36-item short-form health survey (SF-36). I. Conceptual framework and item selection. Med Care 30:473-483

19. Akai M, Doi T, Fujino K, Iwaya T, Kurosawa H, Nasu T (2005) An outcome measure for Japanese people with knee osteoarthritis. J Rheumatol 8:1524-1532

20. Veenhof C, Huisman PA, Barten JA, Takken T, Pisters MF (2012) Factors associated with physical activity in patients with osteoarthritis of the hip or knee: a systematic review. Osteoarthr Cartil 20:6-12

21. Fukutani N, Iijima H, Aoyama T, Yamamoto Y, Hiraoka M, Miyanobu K, Jinnouchi M, Kaneda E, Tsuboyama T, Matsuda S (2016) Knee pain during activities of daily living and its relationship with physical activity in patients with early and severe knee osteoarthritis. Clin Rheumatol 35:2307-2316

22. Kellgren JH, Lawrence JS (1957) Radiological assessment of osteoarthrosis. Ann Rheum Dis 16:494-502

23. Iijima H, Fukutani N, Aoyama T, Fukumoto T, Uritani D, Kaneda E, Ota K, Kuroki H, Matsuda S (2016) Clinical impact of coexisting patellofemoral osteoarthritis in Japanese patients with medial knee osteoarthritis. Arthritis Care Res (Hoboken) 68:493-501

24. Watkins MA, Riddle DL, Lamb RL, Personius WJ (1991) Reliability of goniometric measurements and visual estimates of knee range of motion obtained in a clinical setting. Phys Ther 71: 90-96

25. Wang CY, Olson SL, Protas EJ (2002) Test-retest strength reliability: hand-held dynamometry in community-dwelling elderly fallers. Arch Phys Med Rehabil 83:811-815

26. Faul F, Erdfelder E, Lang AG, Buchner A (2007) G*power 3: a flexible statistical power analysis program for the social, behavioral, and biomedical sciences. Behav Res Methods 39:175-191

27. Cohen J (1988) Statistical power analysis for the behavioral sciences, 2nd edn. Lawrence Erlbaum, Hillsdale

28. Peduzzi P, Concato J, Kemper E, Holford TR, Feinstein AR (1996) A simulation study of the number of events per variable in logistic regression analysis. J Clin Epidemiol 49:1373-1379

29. Vickers AJ (2006) How to randomize. J Soc Integr Oncol 4:194 198

30. Segal NA, Boyer ER, Wallace R, Torner JC, Yack HJ (2013) Association between chair stand strategy and mobility limitations in older adults with symptomatic knee osteoarthritis. Arch Phys Med Rehabil 94:375-383

31. van Dijk GM, Veenhof C, Spreeuwenberg P, CARPA Study Group et al (2010b) Prognosis of limitations in activities in osteoarthritis of the hip or knee: a 3-year cohort study. Arch Phys Med Rehabil 91: 58-66

32. Sharma L, Dunlop DD, Cahue S, Song J, Hayes KW (2003) Quadriceps strength and osteoarthritis progression in malaligned and lax knees. Ann Intern Med 138:613-619

33. Pai YC, Chang HJ, Chang RW, Sinacore JM, Lewis JL (1994) Alteration in multijoint dynamics in patients with bilateral knee osteoarthritis. Arthritis Rheum 37:1297-1304

34. Neumann DA (2010) Kinesiology of the hip: a focus on muscular actions. J Orthop Sports Phys Ther 40:82-94

35. Neumann DA, Soderberg GL, Cook TM (1988) Comparison of maximal isometric hip abductor muscle torques between hip sides. Phys Ther 68:496-502

36. Stansfield BW, Nicol AC (2002) Hip joint contact forces in normal subjects and subjects with total hip prostheses: walking and stair and ramp negotiation. Clin Biomech (Bristol, Avon) 17:130-139

37. Tevald MA, Murray A, Luc BA, Lai K, Sohn D, Pietrosimone B (2016) Hip abductor strength in people with knee osteoarthritis: a 
cross-sectional study of reliability and association with function. Knee 23:57-62

38. Hortobágyi T, Westerkamp L, Beam S et al (2005) Altered hamstring-quadriceps muscle balance in patients with knee osteoarthritis. Clin Biomech (Bristol, Avon) 20:97-104

39. Bouchouras G, Patsika G, Hatzitaki V, Kellis E (2015) Kinematics and knee muscle activation during sit-to-stand movement in women with knee osteoarthritis. Clin Biomech (Bristol, Avon) 30:599-607

40. Tuna S, Balcı N, Özçakar L (2016) The relationship between femoral cartilage thickness and muscle strength in knee osteoarthritis. Clin Rheumatol 35:2073-2077

41. Omori G, Koga Y, Tanaka M et al (2013) Quadriceps muscle strength and its relationship to radiographic knee osteoarthritis in Japanese elderly. J Orthop Sci 18:536-542
42. Chang AH, Moisio KC, Chmiel JS, Eckstein F, Guermazi A, Prasad PV, Zhang Y, Almagor O, Belisle L, Hayes K, Sharma L (2015) External knee adduction and flexion moments during gait and medial tibiofemoral disease progression in knee osteoarthritis. Osteoarthr Cartil 23:1099-1106

43. Amin S, Luepongsak N, McGibbon CA, LaValley MP, Krebs DE, Felson DT (2004) Knee adduction moment and development of chronic knee pain in elders. Arthritis Rheum 51:371-376

44. Kito N, Shinkoda K, Yamasaki T et al (2010) Contribution of knee adduction moment impulse to pain and disability in Japanese women with medial knee osteoarthritis. Clin Biomech (Bristol, Avon) 25:914-919 